\title{
Study on Effect of UHV Power Grid Construction Schemes on Short Circuit Current
}

\author{
Zaihua Li'1 Feng Gao², Qing Wang1, Shuang Zhang2, Hongmei Luo', Jian Liang² \\ ${ }^{1}$ China Electric Power Research Institute, Beijing, China \\ ${ }^{2}$ Ningxia Electric Power Research Institute, Yinchuan, China \\ Email: lizaihua@epri.sgcc.com.cn
}

Received January 2015

\begin{abstract}
The commissioning of Southern Hami-Zhengzhou $\pm 800 \mathrm{kV}$ UHVDC transmission project has important significance to heighten operation reliability, transfer capability and supply electric ability of Henan power grid. However, short circuit currents of $500 \mathrm{kV}$ buses in the Center of Henan are almost close to the operation upper limitation. In order to decrease the short circuit currents effectively, it's necessary to strengthen the network structure of Center of Henan power grid and calculate short circuit currents. Two schemes of strengthening the network structure of Center of Henan power grid are studied. The calculated values of short circuit currents of some important $500 \mathrm{kV}$ buses in the two schemes are still bigger than excepted. According to the latest Plan of State Grid, Yubei UHV substation and Zhumadian UHV substation located in Henan power grid. The calculated values of short circuit currents of some important $500 \mathrm{kV}$ buses with the commissioning of Yubei UHV and Zhumadian UHV are qualified. So, reasonable network structure with UHV is suitable to heighten transfer capability and supply electric ability of Henan power grid.
\end{abstract}

\section{Keywords}

UHV, UHVDC, Construction Scheme, Short Circuit Current

\section{Introduction}

By the year of 2014, the main network structure of Henan power grid is a $500 \mathrm{kV}$ trapezoid structure with two vertical and four horizontal lines. In 2013, peak load of Henan power grid is about 48,010 MW, while the generate ability of Henan power grid is only 46,260 MW. Therefore, there's a power shortage more than $3000 \mathrm{MW}$ when considering reserved capacity. The installed capacity of coal-fired thermal power units accounted for 90 percent of the total installed capacity of Henan province. Considered from environment protection and sustainable development point of view, the commissioning of Southern Hami-Zhengzhou \pm 800 kV UHVDC transmission project (i.e. Hami-Zhengzhou UHVDC) has important significance to heighten operation reliability, transfer capability and supply electric ability of Henan power grid.

The load center of Henan locates in the Center of Henan power grid, and the power comes from North of Henan,

How to cite this paper: Li, Z.H., Gao, F., Wang, Q., Zhang, S., Luo, H.M. and Liang, J. (2015) Study on Effect of UHV Power Grid Construction Schemes on Short Circuit Current. Journal of Power and Energy Engineering, 3, 200-205. 
West of Henan and South of Henan, so the suitable location of Henan power grid integrating Hami- Zhengzhou UHVDC is the Center of Henan power grid. However, short circuit currents of $500 \mathrm{kV}$ buses in Center of Henan power grid are almost close to the operation upper limitation. In order to decrease the short circuit currents effectively, it's necessary to improve and strengthen the network structure of the Center of Henan power grid and calculate short circuit currents in the new network structure [1].

\section{Effect of Short Circuit Current}

Short circuit current calculation and control is one of the most important functions in power system analysis. Effect of short circuit current can be summarized as below [2]:

1) Short circuit is a kind of serious fault, it may break the stable operation of power system, break the power supply and even bring blackout.

2) It will decrease the voltage of power system greatly, damage industry equipment and product, and debase the quality of power energy.

3) The flaring electric arc may burn out the equipment, and if the short circuit current exceeds the interrupting ability of breaker, it may cause more serious fault.

4) It brings thermo effect and electromotive force effect, they may damage the equipment.

5) Short circuit current may disturb communication system and electronic system nearby.

However, short circuit current is far from having no benefit. Bigger short circuit current means stronger ability to tolerate serious short circuit fault for a certain power system. In order to ensure the security and stability of power system, it's necessary to keep a certain short circuit current level and control the short circuit current within an appropriate range.

\section{Analysis of Short Circuit CURRENT}

\subsection{Calculation Conditions of Short Circuit Current}

The calculation conditions of short circuit current in the paper are as below [3] [4]:

1) Calculating result is the effective value of industrial frequency current component injected into the short circuit point at the moment at which the short circuit arises.

2) The three-phase AC system is a symmetrical system, the structures of three phases of stator windings are symmetrical, and the spatial position differs by $120^{\circ}$ electrical angle.

3) The short circuit is a bolted fault, and the short circuit impedance in the fault point has a value of zero.

4) To suppose the quadrature axis subtransient reactance is equal to the direct axis subtransient reactance. The model of synchronous generator with the direct axis subtransient reactance and constant subtransient electromotive force is used. The magnetic saturation effect of generator and the skin effect of conductor aren't considered.

5) Magnetic saturation effect of static components isn't considered, parameters of electric equipment won't change with the value of current.

6) The tap of transformer is used with the actual setting.

7) The operation mode of Henan power grid is with all generators and all lines operated, the load model of constant impedance load and induction motor is used.

\subsection{Short Circuit Current of $500 \mathrm{kV}$ System in Henan in 2013}

The calculation results of three-phase short circuit current of some important $500 \mathrm{kV}$ buses in Henan power grid in 2013 are shown in Table $\mathbf{1 .}$

From the above table, if the induction motor model was considered, then three-phase short circuit current of some important $500 \mathrm{kV}$ buses in Center of Henan power grid will exceed $63 \mathrm{kA}$. In fact the calculation conditions of short circuit current are somewhat conservative. In order to keep pace with the actual status in field, induction motor may be not taken into account in the succeeding study. Even if the induction motor isn't taken into account, the maximum value of three-phase short circuit current in Henan power grid is close to the limit breaking capacity of breaker. It’s necessary to decrease short circuit current by some measures.

\subsection{Short Circuit Current of $500 \mathrm{kV}$ System in Henan in 2014}

The calculation results of three-phase short circuit current of some important $500 \mathrm{kV}$ buses in Henan power grid 
in 2014 are shown in Table 2.

From the above table, short circuit current level of the Henan power grid is increasing accordingly year by year because of the growth of economy, and short circuit current problem is more obvious. Even if the induction motor isn't taken into account, the three-phase short circuit current in Henan power grid is enlarged and closer to the limit breaking capacity of breaker. So it's urgent necessary to decrease short circuit current by some measures.

\section{Two Schemes of Strengthening the Network Structure}

To heighten the breaking ability of breaker is a directional way, but now the breaker with breaking ability above $63 \mathrm{kA}$ is too much expensive. In general, it's not economical to use breaker with breaking ability above $63 \mathrm{kA}$ widely. In order to ensure the security of power system, to strengthen and improve the network structure is a better choice by far now.

According to the characteristic of Henan power grid and source of short circuit current in some important $500 \mathrm{kV}$ buses, the network structure can be improved and optimized. The strengthening measures can't do much harm to the security and stability of power system. When considering all-round, two schemes of improving and strengthening the network structure of Center of Henan power grid are studied as below [5].

\subsection{Scheme No. 1 .}

The network structure of Center of Henan power grid of strengthening scheme 1 is shown in Figure 1 as below.

The $1^{\text {st }}$ scheme is to connect one of Songshan-Zhengzhou double circuit $500 \mathrm{kV}$ transmission lines and one of Zhengzhou-Guandu double circuit $500 \mathrm{kV}$ transmission lines in series outside the $500 \mathrm{kV}$ Zhengzhou Substation. Calculation verified that the strengthening measures won't do much harm to the security and stability of power system. The network structure meets the requirement of Guide on Security and Stability for Power System (DL 755 - 2001). The calculation result of three-phase short circuit current of strengthening scheme 1 is shown in table 3 as below.

Table 1. Short circuit currents of some important $500 \mathrm{kV}$ buses in 2013.

\begin{tabular}{ccc}
\hline & & short circuit current (kA) \\
\cline { 2 - 3 } Bus & With motor & 60.03 \\
YU_Songshan50 & 67.42 & 59.31 \\
YU_Zhengzhou50 & 66.42 & 55.14 \\
YU_Huojia50 & 62.51 & 56.15 \\
YU_Zhengbei50 & 62.44 & 47.06 \\
YU_Zhengnan50 & 50.68 & 45 \\
\hline
\end{tabular}

Table 2. Short circuit currents of some important $500 \mathrm{kV}$ buses in 2014.

\begin{tabular}{ccc}
\hline \multirow{2}{*}{ Bus } & \multicolumn{2}{c}{ short circuit current (kA) } \\
\cline { 2 - 3 } & With motor & Without motor \\
\hline YU_Songshan50 & 68.91 & 61.23 \\
YU_Zhengzhou50 & 66.63 & 59.33 \\
YU_Huojia50 & 62.70 & 55.31 \\
YU_Zhengbei50 & 62.41 & 55.96 \\
YU_Zhengnan50 & 50.74 & 47.08 \\
YU_Xiangshan50 & 59.21 & 54.04 \\
\hline
\end{tabular}




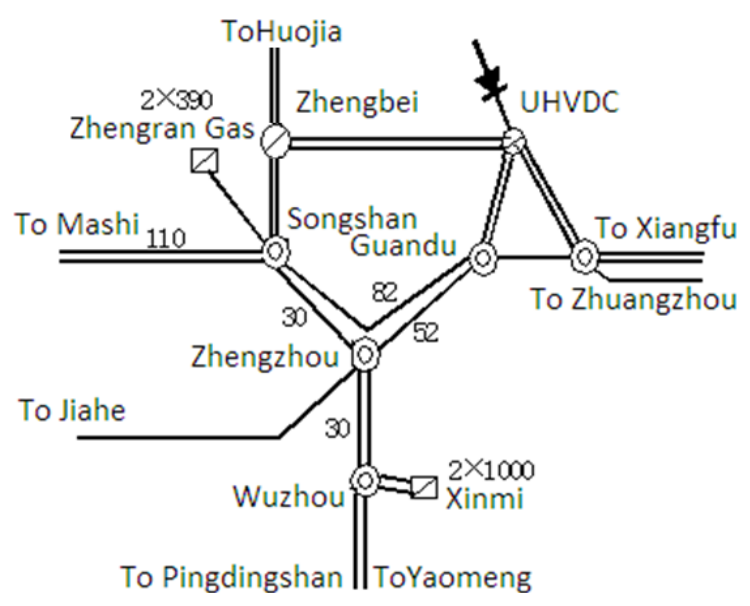

Figure 1. Scheme 1 of strengthening the network.

\subsection{Scheme No. 2}

The network structure of Center of Henan power grid of strengthening scheme 2 is shown in Figure 2 as below.

The $2^{\text {nd }}$ scheme is to open the Songshan-Zhengzhou $500 \mathrm{kV}$ double-circuit transmission lines, so as to enlarge the ring network in Center of Henan power grid. The new $500 \mathrm{kV}$ ring network in Center of Henan is comprised by lines of Songshan-Mashi-Gongyi-Mudan-Jiahe-Zhengzhou-Guandu-Zhengzhou UHVDC convertor substation-Zhengbei-Songshan. Calculation verified that the measures won't do much harm to the security and stability of power system. The network structure meets the requirement of Guide on Security and Stability for Power System (DL 755 - 2001) [6]. The calculation results of three-phase short circuit current of some important 500 $\mathrm{kV}$ buses in strengthening scheme 1 and scheme 2 are shown in Table 3 as below.

From the above table, it's obvious that the calculated values of short circuit currents are still bigger than except. They are still close to the limit breaking capacity of breaker. The two strengthening schemes only have obvious effect on relative substations, and have little effect on other substations.

\subsection{Scheme No. 2 with Yubei UHV and Zhumadian UHV}

According to the latest Plan of State Grid, Henan UHV power grid will be an important constituent part of the national UHV power grid. There are 2 vertical transmission passageways and 1 horizontal transmission passageway go across Henan UHV power grid. The 1000-kVYubei UHV substation locates in North of Henan, and it has 4 outgoing lines of $500 \mathrm{kV}$. And, the 1000-kV Zhumadian UHV substation locates in South of Henan, and it also has 4 outgoing lines of $500 \mathrm{kV}$.

The calculated values of short circuit currents of some important $500 \mathrm{kV}$ buses with the commissioning of Yubei UHV substation and Zhumadian UHV substation based on the scheme 2 are shown in Table 4.

From the above table, it's obvious that the calculated values of short circuit currents with the commissioning of Yubei UHV substation and Zhumadian UHV substation are smaller than the foregoing two strengthening schemes. It can effect on more substations than the scheme without Yubei UHV substation and Zhumadian UHV substation.

In order to integrate Hami-Zhengzhou UHVDC project, the network structure of Center of Henan power grid has to be strengthened. In the future, the commissioning of Yubei UHV substation and Zhumadian UHV substation also will strengthen the Henan power grid.

It's all known that if a power network is strengthened, in general the short circuit current will be enlarged accordingly. So it's interesting that why the short circuit current be decreased in Henan power grid.

\subsection{The Venin Equivalent Reactance of the Power System}

In order to verify the above simulation and analysis, the The venin equivalent reactance of the power system is calculated [7]. In the Scheme No. 2 without Yubei UHV and Zhumadian UHV, the $1^{\text {st }} 500 \mathrm{kV}$ bus in Zhengzhou substation is selected as the short circuit point. The venin equivalent reactance is about in the range of 0.015621 


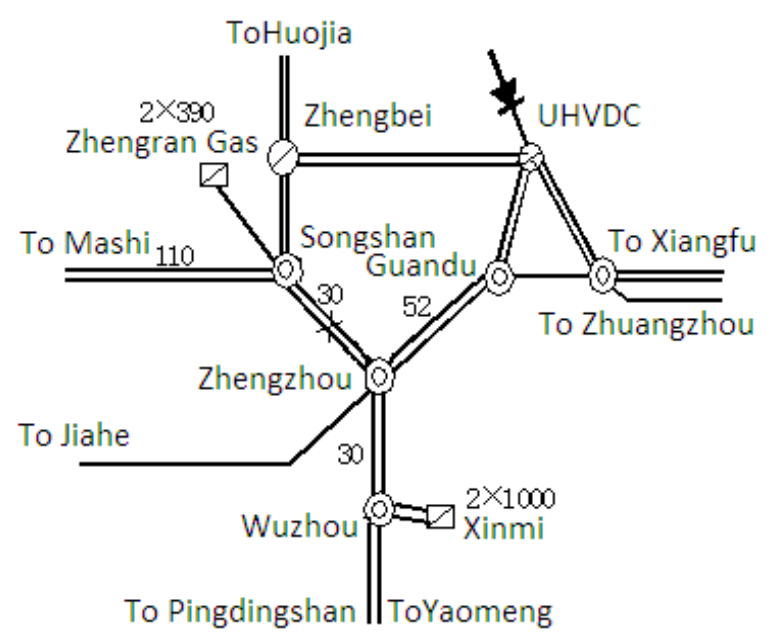

Figure 2. Scheme 2 of strengthening the network.

Table 3. Short circuit currents of strengthening scheme in 2014.

\begin{tabular}{cccc}
\hline \multirow{2}{*}{ Bus } & \multicolumn{3}{c}{ short circuit current (kA) } \\
\cline { 2 - 4 } & Original & Scheme 1 & Scheme 2 \\
\hline YU_Songshan50 & 61.23 & 58.94 & 58.91 \\
YU_Zhengzhou50 & 59.33 & 50.24 & 48.93 \\
YU_Huojia50 & 55.31 & 54.83 & 54.66 \\
YU_Zhengbei50 & 55.96 & 54.73 & 55.20 \\
YU_Zhengnan50 & 47.08 & 46.62 & 46.09 \\
YU_Xiangshan50 & 54.04 & 53.75 & 53.72 \\
\hline
\end{tabular}

Table 4. Short circuit currents of some important 500 kV buses with UHV in 2014.

\begin{tabular}{ccc}
\hline \multirow{2}{*}{ Bus } & \multicolumn{2}{c}{ short circuit current (kA) } \\
\cline { 2 - 3 } & Original & Scheme 2 with UHV \\
\hline YU_Songshan50 & 61.23 & 45.62 \\
YU_Zhengzhou50 & 59.33 & 44.48 \\
YU_Huojia50 & 55.31 & 50.25 \\
YU_Zhengbei50 & 55.96 & 46.21 \\
YU_Zhengnan50 & 47.08 & 44.16 \\
YU_Xiangshan50 & 54.04 & 52.36 \\
\hline
\end{tabular}

- 0.015722. In the Scheme No. 2 with Yubei UHV and Zhumadian UHV, the venin equivalent reactance is about in the range of 0.015685 - 0.015791 . With the commissioning of Yubei UHV substation and Zhumadian UHV substation and other relational improvements in Henan power grid, the venin equivalent reactance of the power system is enlarged in some degree, so the short circuit current is decreased.

The network structure of Henan power grid has been optimized so as to integrate Hami-Zhengzhou UHVDC project. Though the network structure is strengthened, the Center of Henan power grid is simplified and sparser, so the venin equivalent reactance of the power system is enlarged. It's the reason of the short circuit current was decreased obviously. The calculation results of the venin equivalent reactance and the short circuit current can 
verify the simulation and analysis from two aspects.

\section{Conclusions}

After the calculation and analysis, conclusions can be obtained as below.

1) There's a big power shortage in Henan power grid and the power-receiving ratio will be higher in the future. And the short circuit current will grow continuously. So, it's necessary to take appropriate measures to decrease short circuit current.

2) According to the operating characteristic of power grid and source of short circuit current, it's feasible to decrease short circuit current by improving and optimizing the network structure while not to do harm to the security and stability of power system.

3) If a network is strengthened, whether the short circuit current will be enlarged or not can be verified by the venin equivalent reactance.

4) Reasonable network structure with UHV is suitable to heighten operation reliability, transfer capability and supply electric ability of Henan power grid, and the short circuit current problem can be solved in a certain degree.

\section{References}

[1] National Power Dispatching and Communication Center (2009) The Report about Research Special Projects Such as Short Circuit Current, Electromagnetic Loop Network and Transmission Capacity Is Low. State Grid Corporation of China, 11. (In Chinese)

[2] Tang, X.J., Li, Z.H., Wu, L.H., et al. (2011) Investigation and Analysis on Short Circuit Current. China Electric Power Research Institute, 06. (In Chinese)

[3] IEC 60909-0:2001 (2001) Short Circuit Currents in Three-Phase Acsystems_-Part 0: Calculation of Currents. 07.

[4] IEEE Standard 241-1990 (1990) Electric Power Systems in Commercial Buildings.

[5] Luo, H.M., Tang, X.J., Li, X.J., et al. (2012) Research on the Adaptability of Structural Strength before and after Commissioning of the Large Capacity Hami-Zhengzhou UHVDC Project. China Electric Power Research Institute. 09. (In Chinese)

[6] State Economic and Trade Commission of the People's Republic of China (2001) Guide on Security and Stability for Power System (DL 755-2001).

[7] Li, Z.H. (2012) Research on Thevenin Equivalent Parameters Based on Time Domain Simulation. China Electric Power Research Institute, 12. (In Chinese) 